\title{
A Review on Electric Wheelchair Innovation to Ease Mobility and As a Rehabilitation Tool for Spinal Cord Impairment Patient
}

\author{
M. H. Muhammad Sidik1, 2, S. A. Che Ghani1, M. Ishak1, W. S. W. Harun1, N. Daud3 \\ 1. Faculty of Mechanical Engineering, Universiti Malaysia Pahang, 26600 Pekan, Pahang, Malaysia \\ 2. Universiti Kuala Lumpur Malaysia France Institute, Seksyen 14, Jalan Teras Jernang, \\ 43650 Bandar Baru Bangi, Selangor. \\ 3. Department of Rehabilitation, Kuliyyah of Allied Health Science, \\ International Islamic University of Malaysia, 25200 Kuantan, Pahang, Malaysia \\ mohdhanafi88@gmail.com, anwarcg@ump.edu.my
}

\begin{abstract}
Wheelchair is used to assist disability people to do daily activities in order to reduce depending on other to continue their living. Adding some device into it, wheelchair can be not only help in mobilization, it can be rehabilitation device to the user. This review paper focus modifications done onto market available wheelchair. Variety types of sensor used to improve the mobility of electric wheelchair and to make it as a rehabilitation tools at the same time.
\end{abstract}

Keywords - Instrumented wheelchair, spinal cord injury, sensors

\section{INTRODUCTION}

For those who are having impairment for lower and upper extremity, wheelchair is one of their ways to move around. These kind of people, tend to be more depressed comparing those who are healthy and wheelchair provide them mobility to ease their day. On the other hands, their depression can be reduced a little bit by moving around. In United States alone, more than 200,000 use wheelchair as their primary means of mobility[1].

The demand for electric wheelchair increasing since the price been reduced and user switching from manual to powered wheelchair[2]. Especially for patient that suffer in higher level of impairment to ease their daily life[3]. Electric wheelchair can be control by a joystick to move forward, backward, turn left and right. But for some patient with severe motor-disabilities, they can't hold the joystick properly to move around on their wheelchair.

Research to improve electric wheelchair started since 30 years ago to make sure all type of severe motor impairments patient has a wheelchair that can be used by them without bring any harm. Harm can be happened when they miss control the joystick and possibility to hit obstacle and wall. For a cerebral palsy or cognitive impairment, high-level spinal cord injury, and quadriplegia patient, they can't control amount of force to push the joystick and over pushing will caused the wheelchair accelerate instantly.

Control algorithm and control techniques should be developed in order to enhance the riding safety for them. Sensors are neededto detect and measure the object and send the signal to processor to be calculated based on algorithm set before. Control techniques is normally for a pediatrics to teach on how to control their wheelchair to move from point A to point B.Basically the objective to modify available electric wheelchair are to ease the mobility by assist the navigation and as rehabilitation tools. This review paper is discussing about type of sensors installedand how it is work to navigate the movement of electric wheelchair and modification to make it as a rehabilitation tool.

This paper is written to gather as much as possible innovation on electric wheelchair for spinal cord impairment patients. Lots of innovation has been done to cater the wheelchair movement control problem faced by the patients. Normal wheelchair can't be control easily because of they has problem to move their arm and finger especially tocontrol the joystick. Different sensors and different algorithm used by many researcher but their objective is the same, to ease patient to control their wheelchair without hitting other object that can cause injury to them. Additional features added by making it as a rehabilitation tools at the same time to speed up recovery process.

A Review on smart wheelchair component system done by Richard Simpson, Edmund LoPresti[4]. They discussed on hardware, software and performance evaluation on 17 smart wheelchair developed from year 1996 to 2002. Variety type of sensors installed such as sonar, infrared, dead reckoning, ultrasonic, gyroscope vision, line tracker, bump sensor and navigation assistance software are well explained. 
Sharmila Ashok wrote a review on innovated wheelchair focus more on hands-free control system from years 1999 to 2013 [5]. Hands-free control wheelchair is not only for disable patient but also for normal people that need to perform other task by their hand while moving around. Wheelchair's control system is based on gesture, electromyography (EMG), electroencephalogram (EEG) and electrooculography (EOG). This paper discuss about the hardware and software installed to control the hands-free wheelchair for each interface. Command to control each wheelchair and performance evaluation are also available in this paper.

This paper gather as much as possible information on innovated electric wheelchair from year 1983 to 2016. Innovation objective is not only focusing on ease the mobility of patient, including also as a rehabilitation tools for spinal cord impairment patient. Combination of sensors to improve the performance of electric wheelchair is needed to reduce possibility of misread the environment, to make rehabilitation exercise more efficient and to increase motivation of patient. Even though in a system that is using more than one sensor must be one sensor will be the dominant that other sensors can't overwrite its signal. The flow of the control process explained in this paper.

Misread the surrounding condition can cause accident to the user during operating electric wheelchair. That's why more than one sensors is needed to make sure surrounding objects are detected by system before the wheelchair is allowed to move even though all of it produce the same output. For example, ultrasonic and infrared is used to measure the distance of the object but both of it installed on the same wheelchair. As a rehabilitation tools, effect of exercise must be $100 \%$ successful to targeted area to speed up the recovery process and patient has high motivation to keep on doing it. If not, rehabilitation period will be longer and demotivate the patient.

Flow of the control process explained for some innovated electric wheelchairs that using more than one sensor to operate. But still there are few innovated electric wheelchairs that are using only one sensor. This is where the algorithm is critically that developer needs to look into to make it easy for user to operate it. Especially to researchers who are using muscle contraction detecting sensor such as electromyography (EMG) and electroencephalogram (EEG). Same goes to efficient rehabilitation electric wheelchair can be built by using correct sensors in order targeted area get the benefit out of it and can keep patient's motivation to continue do the exercise.

The objective of innovation on electric wheelchair can be divided into two. First one is to ease the mobility and number two is as a rehabilitation tool for spinal cord impairments patient. Not all electric wheelchair that innovated to ease mobility can provide rehabilitation exercise to the user. But electric wheelchair built for rehabilitation exercise, it can ease mobility of user at the same time. Type of sensors for each objective is the same but how the control system works is different as explained further in this paper.

\section{To EASE The MobiLity}

Modifications are not only done to manual wheelchair, electric wheelchairs are also been focused by researchers to improve its mobility. As shown in Table 2, all are electric wheelchair modifications. Since for electric wheelchair, amount of force needed to move is not problem at all, so the researchers made improvement on navigation system.

In 1999, NavChair a Assistive Wheelchair Navigation System been developed to reduce the cognitive and physical requirements of operating a power wheelchair for people with wide ranging impairments that limit their access to powered mobility[6]. During this time, Navchair is equipped with ultrasonic sensor, and DOSbased computer to avoid obstacles, door passage, and move along the wall. In 2002, NavChair's feature upgraded by adding voice control as viable control alternative[7]. Voice control itself is impossible to do small adjustment in wheelchair's velocity because of voice's limited bandwidth. Combination between voice control and sonar sensors make the NavChair able to detect for misinterpreted commands for a better navigation assistance. NavChair' navigation assistance helps in small adjustments in speed and direction necessary to overcome obstacles.

Pediatrics electric wheelchair is also one of research area focused by researchers. Almost all the research are using electric wheelchair because of the size and propelling it is a cognitively challenging task of manual wheelchair that not suit to pediatric. Miguel Sarabia and Yiannis Demiris integrated a Nao to a electric wheelchair in order to lowering the cognitive requirements needed for controlling the movement[8].

Nao is a humanoid robot developed since 2004 and can be programmed based on what type of work planned for the robot. In this research, Nao is used to improvethe mobility of pediatric wheelchair by detecting obstacles, and informing the user not hit the objects. For the result, children are enjoying driving their wheelchair with companion of Nao and at the same time they can do exercise to improve their condition. As shown is Table 1, researches done on electric wheelchair. As shown in Table 1, innovations done on electric wheelchair. 
Table 1: Innovations on automatic wheelchair for spinal cord impairment person

\begin{tabular}{|c|c|c|c|c|}
\hline No & References & Modifications & $\begin{array}{l}\text { No of Hand } \\
\text { Driven }\end{array}$ & $\begin{array}{l}\text { Year } \\
\text { Published }\end{array}$ \\
\hline 1 & [9] & Electric wheelchair & One & 1983 \\
\hline 2 & {$[10]$} & Sonar, infrared, bumper & One & 1990 \\
\hline 3 & [11] & Infrared, ultrasonic & One & 1993 \\
\hline 4 & $\operatorname{Tin} \operatorname{Man}[12]$ & Sonar, infrared, bump & One & 1995 \\
\hline 5 & {$[13]$} & Camera & One & 1996 \\
\hline 6 & [14] & Algorithm positioning & One & 1997 \\
\hline 8 & Senario[15] & Microphone, ultrasonic & One & 1997 \\
\hline 7 & {$[16]$} & Sonar & One & 1997 \\
\hline 9 & Wheelesley[17] & Ultrasonic, infrared, hall effect & One & 1998 \\
\hline 10 & Navchair $[6,7]$ & Ultrasonic,mic & Zero & 1999 \\
\hline 11 & {$[18]$} & Ultrasonic & One & 2000 \\
\hline 12 & Maid[19] & Ultrasound, sonar, infrared & One & 2001 \\
\hline 13 & SIAMO[20] & Vision, ultrasonic, infrared & One & 2001 \\
\hline 14 & WATSON[21] & Camera & One & 2001 \\
\hline 15 & {$[22]$} & Positioning & Both & 2002 \\
\hline 16 & [23] & Camera, ultrasonic & One & 2003 \\
\hline 17 & [24] & Emg, ccd camera, sonar, mic & Zero & 2003 \\
\hline 18 & Smartchair [25] & Camera & One & 2003 \\
\hline 19 & CWA[26-28] & Barcode scanner, PA pr & Both & 2008 \\
\hline 21 & [29] & Line follower, robot & One & 2010 \\
\hline 23 & {$[30]$} & Infrared ,sonar & One & 2011 \\
\hline 22 & {$[31]$} & Microphone & One & 2011 \\
\hline 24 & [32] & Webcam, Kinect, infrared, & One & 2012 \\
\hline 26 & {$[8]$} & Robot NAO & One & 2013 \\
\hline 25 & {$[33]$} & Infrared, mic & Zero & 2013 \\
\hline 27 & IRC[34] & Robot arm, camera & One & 2014 \\
\hline 28 & {$[35]$} & electrooculogram & Zero & 2014 \\
\hline 29 & {$[36]$} & Tilt sensor & One & 2015 \\
\hline 30 & {$[37]$} & EMG & One & 2015 \\
\hline 31 & {$[38]$} & EMG, camera & One & 2015 \\
\hline 32 & [39] & Camera, wireless control & One & 2016 \\
\hline 32 & {$[40]$} & Camera & One & 2016 \\
\hline 33 & [41] & Ultrasonic, fuzzy & One & 2016 \\
\hline 34 & {$[42]$} & Accelerometer, Infrared, ultrasonic & One & 2016 \\
\hline 35 & [43] & Electroencephalogram EEG & One & 2016 \\
\hline 36 & [44] & Accelerometer & One & 2016 \\
\hline 37 & {$[45]$} & Ultrasonic & One & 2016 \\
\hline 42 & {$[46]$} & Size of joystick & One & 2016 \\
\hline 38 & {$[47]$} & Tele-conference, pressure sensor & One & 2016 \\
\hline 39 & [48] & Ultrasonic, microphone & One & 2016 \\
\hline 40 & [49] & Infrared , microphone & One & 2016 \\
\hline 41 & {$[50]$} & Infrared, microphone, accelerometer, & One & 2016 \\
\hline 43 & [51] & electroencephalographic (EEG) & One & 2016 \\
\hline 44 & {$[52]$} & Laser range & One & 2016 \\
\hline 45 & {$[53]$} & EMG, solar & One & 2016 \\
\hline 46 & [54] & Infrared & One & 2016 \\
\hline
\end{tabular}




\begin{tabular}{|l|l|l|l|l|}
\hline 47 & {$[55]$} & EMG & One & 2016 \\
\hline 48 & {$[56]$} & accelerometer & One & 2016 \\
\hline 51 & {$[57]$} & EMG & One & 2016 \\
\hline 52 & {$[58]$} & EMG ,accelerometer, gyroscope & One & 2016 \\
\hline 53 & {$[59]$} & EMG & One & 2016 \\
\hline 54 & {$[60]$} & Infrared, kinect & One & 2016 \\
\hline 55 & HanGes[61] & Infrared & One & 2016 \\
\hline 56 & {$[62]$} & EEG, laser scanner & One & 2016 \\
\hline 57 & {$[63]$} & EEG & One & 2016 \\
\hline
\end{tabular}

\section{TYPE OF SENSORS INSTALLED}

\section{A. Signal}

Wheelchairs have been developed in a aggressively for the past years. Most of the innovation on wheelchair are by improving the mobility and riding security at the same time by adding more features such as avoiding obstacles. But, not all features are not equal in importance and interest to all patient for upper limb. So, lot of different sensors are equipped to find the best solution. Sensors are used send signal before any action taken by the actuator to move around.

\section{B. Sound wave detector sensor}

There are 2 type of sound wave detecting sensor available in the market to detect any object in some certain range. Sonar and ultrasonic sensor widely used to improve mobility of electric wheelchair. Sonar (Sound Navigation And Ranging) used by submarine to communicate or detect any obstacles in front of it to move without hitting any objects. In 1997, this technique has been implemented into electric wheelchair by A. Bühlmeier, M. Rossmann, K. Goser, . Manteuffel to measure the distance (between object and sensor) and send signal to microcontroller to reduce the voltage amount to the motor[16].

Since using sonar sensor produce a slow ping sound, Navchair has been developed by using ultrasonic sensor to detect the obstacles $[6,7]$. Ultrasonics are the frequencies above the level ofhuman hearing which is more than $20 \mathrm{kHz}$. Navchair developed by Simon P. Levine, David A. Bell, Lincoln A and their team to build a navigation system to reduce the cognitive and physical requirements of operating a power wheelchair for people with wide ranging impairments that limit their access to powered mobility.

Microphone added into Navchair to identify sound signal and transmits to computer and match it with joystick command to steer it to left or right. 12 Sonarsensors used as additional to improve the navigation. Sonar sensors alone is not good enough and possibility to make error is high. Error Eliminating Rapid Ultrasonic Firing (EERUF) techniques implemented to reduce the error and wheel counter keeping track of wheelchair's motion. Combination of this 2 obstacle detection method reduce the mistake in reading the signal to navigate the wheelchair better. Figure 1 below shows overview of Navchair Assistive Wheelchair Navigation System.

Same things done for SIAMO in 2001. A microphone equipped to add extra features to navigate the wheelchair to make it easier for the user. Signal from environment perception sensors (ultrasonic, infrared) is match with signal from human-machine Interfaces (microphone, head movement, joystick) to send information to motion controller to move based on commands[20]

Smart Pediatric Wheelchair developed by department of Electric and Electronic Engineering Imperial College London called Assistive Robot Transport for Youngsters (ARTY) in 2011[30]. Pediatrics powered wheelchair is difficult to develop due to safety concerns since young children can't follow instruction properly because their attention can easily change in any time. To make them focus, toys used to make sure they control ARTY to find hidden items placed around the lab. 10 sonar sensors installed under the rim bar to perceive the surrounding to prevent ARTY from hitting wall or obstacles. 
TABLE 2. Sound Wave Detector Sensor

\begin{tabular}{|l|l|c|c|}
\hline No & References & Target Group & Year Published \\
\hline 1 & {$[10]$} & Adult & 1990 \\
\hline 2 & {$[11]$} & Adult & 1993 \\
\hline 3 & Tin Man[12] & Adult & 1995 \\
\hline 4 & Senario[15] & Adult & 1997 \\
\hline 5 & {$[16]$} & Adult & 1997 \\
\hline 6 & 3 Wheelesley[17] & Adult & 1998 \\
\hline 7 & Navchair[6,7] & Adult & 1999 \\
\hline 8 & {$[18]$} & Adult & 2000 \\
\hline 9 & Maid[19] & Adult & 2001 \\
\hline 10 & SIAMO[20] & Adult & 2001 \\
\hline 11 & {$[23]$} & Adult & 2003 \\
\hline 12 & {$[24]$} & Adult & 2003 \\
\hline 13 & {$[30]$} & Adult & 2011 \\
\hline 14 & {$[41]$} & Adult & 2016 \\
\hline 15 & {$[42]$} & Adult & 2016 \\
\hline 16 & {$[45]$} & Adult & 2016 \\
\hline 17 & {$[47]$} & Adult & 2016 \\
\hline 18 & {$[48]$} & Adult & 2016 \\
\hline 19 & {$[50]$} & Adult & 2016 \\
\hline
\end{tabular}

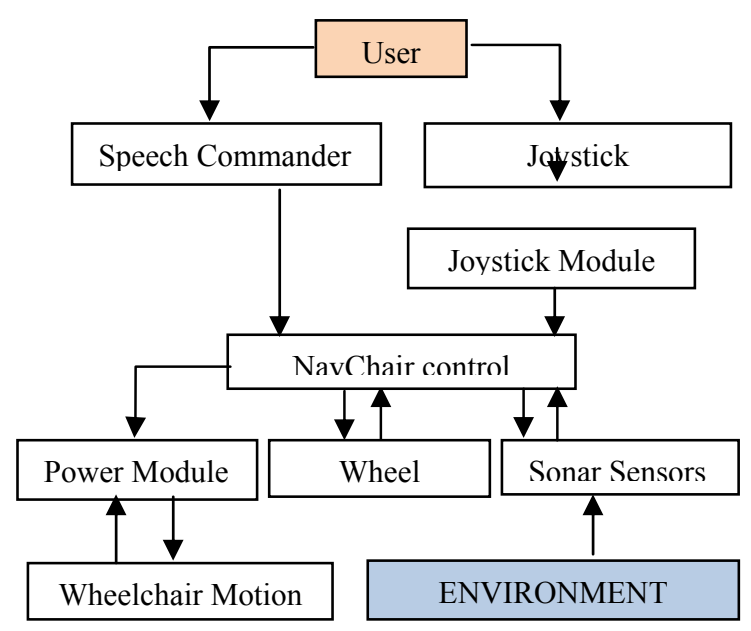

Fig. 1. Navchair Assistive Wheelchair Navigation System

\section{Voice recognition}

Voice or audio is an analog signal which is needed to be converted into digital signal in order for computer to read the signal. All speech patterns are stored inside the drive and when the system running, it will use the memory to match with what command send by user. Researcher installed microphone to record the analog signal and use that signal as command to control the wheelchair. For paraplegia and tetraplegia patient, producing audio signal is not a problem and that's why it become choice for most researcher to gain signal to innovate current wheelchair.

However, some voice-recognition systems make errors by detecting sound from environment such as other people conversation, audio from television, radio and many more. These disturbance can produce false input and will affect the smoothness of wheelchair movement. To overcome this matter, Akira Sasou combining signal form user's head gesture and voice to move the wheelchair [31]. As the result is average recognition accuracy was $99.7 \%$. 
Bharati Vidyapeeth University did the same thing by implementing additional sensor to reduce mistake in interpreting signal by adding infrared to their wheelchair[33]. Stored voice commands are Forward, Reverse, Left, Right and Stop and user need to use all these 5 commands to control the wheelchair. Voice signal recognize from microphone will be recognize the pattern by Matlab and at the same time signal from infrared come together to detect obstacles at the surrounding. All these 2 signals will be processed and if there is obstacle in the way, buzzer will beep and stop the wheelchair to prevent any bad things happens as in Figure 2.

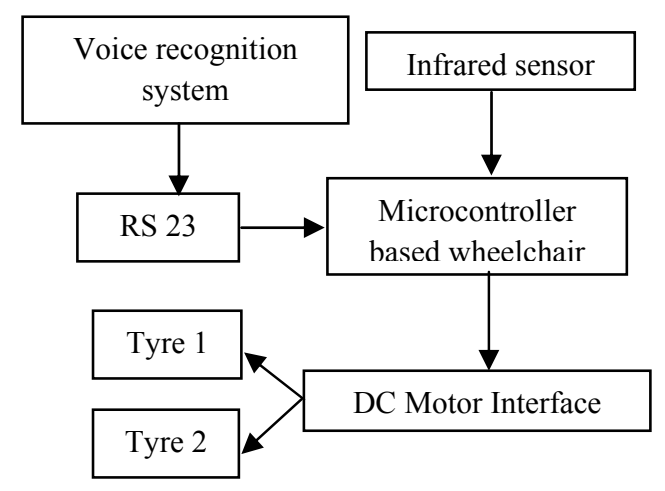

Fig. 2. Overview of navigation system

Fig 1TABLE 3. Voice Recognition

\begin{tabular}{|l|l|l|l|}
\hline No & References & Target Group & Year Published \\
\hline 1 & Senario[15] & Adult & 1997 \\
\hline 2 & Navchair[6, 7] & Adult & 1999 \\
\hline 3 & {$[24]$} & Adult & 2003 \\
\hline 4 & {$[31]$} & Adult & 2011 \\
\hline 5 & {$[33]$} & Adult & 2013 \\
\hline 6 & {$[48]$} & Adult & 2016 \\
\hline 7 & {$[49]$} & Adult & 2016 \\
\hline 8 & {$[50]$} & Adult & 2016 \\
\hline
\end{tabular}

\section{Infrared}

Infrared works almost same as ultrasonic and sonar. Both has emitter and receiver to detect object's distance in front of us. Normally infrared is used to measure thermal energy in certain object that produce heat. But in this case Maid has used it as short-range motion detector[19]. Laser finder and sonar installed together to navigate Maid for its main task which is navigating in a crowded areas is to reach a targeted area without hitting any objects.

Navigating in crowded area require Maid's computer to has maneuver for every $0.3 \mathrm{~s}$ because of using short range motion detector that need to detect fast to avoid collision. Even though infrared maneuver is around $70 \mathrm{~ms}$, but since it connected to low transmission rate of the range-finder it become $0.3 \mathrm{~s}$. Maid tested in central station of Ulm Germany duringrush-hour and in the exhibition halls of the Hannover Messe and it lasted for 36 hours in public, crowded environments with heavy passenger traffic.

MIT developed Wheelesley which used 3 type of sensors, infrared, sonar and Hall Effect sensor. All these 3 sensors are used especially in indoor environment to provide users with driving assistance, taking over low-level navigation to allow its user to travel efficiently[17]. For wheelesley, infrared sensor which give binary readings that indicate if there is something blocking in one foot distance if sonar sensors unable to detect it.

Sonar reading sometimes effected because of noisy environment and will send wrong signal to controller. So infrared act more dominantly compare to sonar sensor. Hall effect sensor is attached to wheelchair bumper as last obstacle detector. It has been tested and bumper hit the obstacle only once for the whole time (10 hours testing time). 
TABLE 4. Infrared Sensor

\begin{tabular}{|l|l|c|c|}
\hline No & References & Target Group & Year Published \\
\hline 1 & {$[10]$} & Adult & 1990 \\
\hline 2 & {$[11]$} & Adult & 1993 \\
\hline 3 & Tin Man[12] & Adult & 1995 \\
\hline 4 & Wheelesley[17] & Adult & 1998 \\
\hline 5 & SIAMO[20] & All & 2001 \\
\hline 6 & {$[30]$} & Paeds & 2011 \\
\hline 7 & {$[33]$} & Adult & 2013 \\
\hline 8 & {$[42]$} & Adult & 2016 \\
\hline 9 & {$[49]$} & Adult & 2016 \\
\hline 10 & {$[50]$} & Adult & 2016 \\
\hline 11 & {$[54]$} & Adult & 2016 \\
\hline 12 & {$[60]$} & Adult & 2016 \\
\hline 13 & HanGes[61] & Adult & 2016 \\
\hline
\end{tabular}

\section{E. Image detection}

Image detection device or camera also has been used to provide guidance in controlling electric wheelchair. Nara Institute of Science and Technology developed a wheelchair (Watson) that can be controlled by using head and gaze motion[21]. Image recorded by a CCD camera which mounted $15^{\circ}$ lower than user head position for easier to observe the irises position because of eyelids tend to occlude the irises when looking and not to block user view. Vertical and horizontal head turning angle observed by camera to either user want to stop, start, turn left or right and speed control. For stop and start, user need to nod their head for $20^{\circ}$ up and down for $2 \mathrm{~s}$. Head turning determine the direction of wheelchair and if movement of head and gaze are not same, Watson will slowdown and turning radius also become bigger to avoid hitting obstacle when the user is not focus.

Intelligent Robotic Chair (IRC) is an autonomous intelligent wheelchair developed based on modified wheelchair called Nosokoma use camera 3D objects by using synthesis of 2D views[34]. In order to recognize it, IRC need to use image segmentation, wavelets, Regions Synthesis Local-Global graphs, and an object-Database (DB).

Some objects have been stored in IRC's database and it make easier for it to detect the location in providing better guidance. IRC also has ability to detect new objects by combining the image from database and interact with human subject to confirm it as obstacle and then save it to improve its knowledge. After recognition stage, the signal is use in process of object detection and tracking. This is where object's distance, size and location are calculated by computer so that IRC's robotic arm-hand can grasp the object as desired by human subject or user. Neural nets and fuzzy algorithms developed to control the robotic arm-hand in grasping method to prevent from breaking the object. Tested on picking up an egg and successfully grasping it and deliver to human subject with breaking it. Cameras are not equipped to detect object location only, it also used to detect human subject location to deliver the desired item. Human subject can be anywhere inside the room and give instructions to IRC via voice interaction system without riding it to picking up anything that they want. Figure 3 shows overview of IRC Navigation system. 


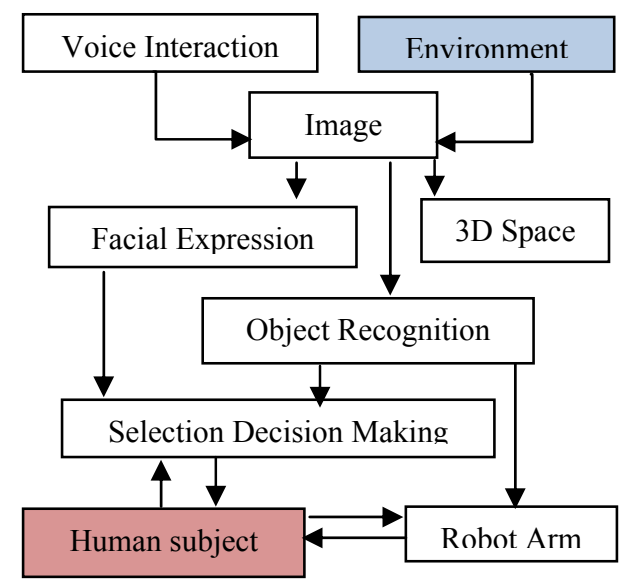

Fig. 3 . Overview of IRC navigation system

Table 5. Image Detection

\begin{tabular}{|l|l|l|l|}
\hline No & References & Target Group & Year Published \\
\hline 1 & {$[13]$} & Adult & 1996 \\
\hline 2 & SIAMO[20] & All & 2001 \\
\hline 3 & WATSON[21] & Adult & 2001 \\
\hline 4 & {$[23]$} & Adult & 2003 \\
\hline 5 & {$[24]$} & Adult & 2003 \\
\hline 6 & Smartchair $[25]$ & Adult & 2003 \\
\hline 8 & {$[32]$} & Adult & 2012 \\
\hline 7 & IRC[34] & Adult & 2014 \\
\hline 9 & {$[38]$} & Adult & 2015 \\
\hline 10 & {$[39]$} & Adult & 2016 \\
\hline 11 & {$[40]$} & Adult & 2016 \\
\hline 12 & {$[47]$} & Adult & 2016 \\
\hline
\end{tabular}

\section{F.Muscle contraction detector}

Every movement of human part is because of muscle. Muscle can do two type of contraction, isometric and isotonic. Isometric when a muscle contracts with no any movement happen and isotonic when muscle shortens (concentric) or lengthens (eccentric). Before all these 3 movement happen, motor neurons transmit electrical signals that cause muscles to contract. Researchers use that electric signal to translate into graphs, sound or numerical values to control wheelchair known as electromyography (EMG).

Researchers from Korea Orthopedics and Rehabilitation Engineering Center proposing to build a robotic wheelchair can be controlled using on electromyogram (EMG) signal, face directional gesture, and voice. Detected signal transfer to human-computer interface to process and wheelchair move as intended by the user. 2 EMG sensors located on both side of levator scapulae muscle (LSM) of user and the signal generated from elevation motions of shoulder. Left shoulder elevation will send signal to turn left and same goes to elevation of right shoulder, it will turn right. Same movement of both levator scapulae muscle will signal the wheelchair to stop and go.

Biswajeet Champaty, Jobin Jose, Kunal Pal control the wheelchair using Electrooculogram (EOG)[35]. They believed that EOG signals is an attractive mechanism for developing human-machine interface because even the terminally-ill patients still has residual eye movement that can be convert into EOG signals. EOG signals appear over the skin surface during the movement of the eye because of the difference in the dipole moment between the retina and the cornea of the eye[64]. Obtained signal from eye movement transfer to LABview to do better filtering for a better result. Then, the signal transmit through radio frequency (RF) to 4 microcontroller to process the signal from 5 EOG sensor before any action taken by the motor. Up, Down, Left, Right and blink represent forward, backward, left, right and stop movement of the wheelchair. 
S. Sathish, K. Nithyakalyani and their team members develop an control system by using EMG signal to control robotic wheelchair for paralysed persons[55]. Flow of the signal process as shown in figure 7. Start from electronic current converted by $\mathrm{Ag}-\mathrm{AgCl}$ surface electrodes from contraction of muscles. Voltage for $\mathrm{EMG}$ signal is between 0 to $5 \mathrm{mV}$ and the frequency is between 0 to $500 \mathrm{~Hz}$. But normally the frequency will be between 50 to $150 \mathrm{~Hz}$ only and noise will be 0 to $10 \mathrm{~Hz}$ and $500 \mathrm{~Hz}$. 0 to $10 \mathrm{~Hz}$ is due to vibration of the equipment and $500 \mathrm{~Hz}$ because there is a movement between EMG electrode and user's skin. High-pass filter used to eliminate the $500 \mathrm{~Hz}$ noise and low-cut filter is for low frequency noise. Filtered signal amplified to $5 \mathrm{~V}$ before goes to microprocessor. Microprocessor works at $5 \mathrm{~V}$. In the amplifier stage, precision rectifier installed to convert bipolar EMG signal to unipolar signal. When user's head is moving, both electrodes will produce different voltage and comparator used to recognize it to determine the direction of movement. Pattern of signal will be recognize by microprocessor to instruct the wheelchair to move forward, turn left or right. Their system tested on prototype and the result is it move forward smoothly but turn left and right need improvement for precise sharp turn.

TABLE 5. Muscle contraction detector sensor

\begin{tabular}{|l|l|l|l|}
\hline No & References & Target group & Year Published \\
\hline 1 & {$[24]$} & Adult & 2003 \\
\hline 2 & {$[35]$} & Adult & 2014 \\
\hline 3 & {$[37]$} & Adult & 2015 \\
\hline 4 & {$[38]$} & Adult & 2015 \\
\hline 5 & {$[43]$} & Adult & 2016 \\
\hline 6 & {$[51]$} & Adult & 2016 \\
\hline 8 & {$[53]$} & Adult & 2016 \\
\hline 7 & {$[55]$} & Adult & 2016 \\
\hline 9 & {$[57]$} & Adult & 2016 \\
\hline 10 & {$[58]$} & Adult & 2016 \\
\hline 11 & {$[59]$} & Adult & 2016 \\
\hline 12 & {$[62]$} & Adult & 2016 \\
\hline 13 & {$[63]$} & Adult & 2016 \\
\hline
\end{tabular}

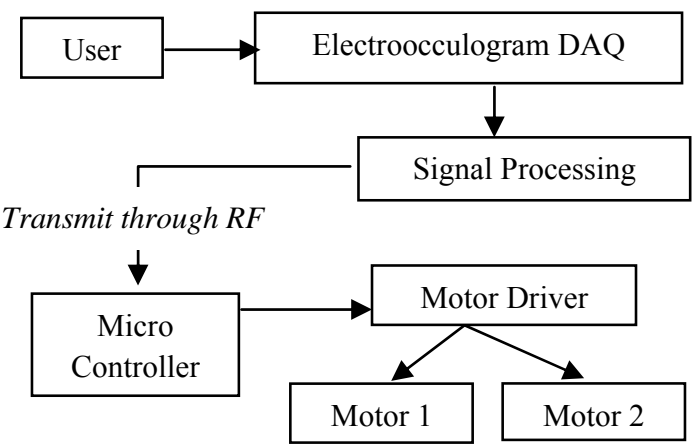

Fig 4 . Overview of navigation system

\section{DESIGN}

Since electric wheelchair is for chronic patient which can't use their upper limb to propel the normal one. It equipped with joystick to control both motors that located on both wheel to remove propulsion effort. Researchers use this advantages to enhance it to fit patient group based on their disability to improve mobility for user. In 1995, DAVID R MILLER developed a low cost robotic wheelchair call TinMan by adding extra control features to a normal electric wheelchair made by Vector Wheelchair Corp[12]. Most of researchers improve current automatic wheelchair with installing another controlling system for the user.

But for companies, in order to build a wheelchair that fit to man as possible, they improve on the capability of their product. Such as ROVI ${ }^{\circ}$ MOBILITY, ltd launched a new automatic wheelchair ROVI X3 that already improved in last longer battery. As we know, automatic wheelchair is very weight and need big amount of energy to move around. A good battery is needed for when the user going outside, their wheelchair have enough power to return to their home. 
One of main problem for wheelchair user to move between floors when there is no lift provided in that building. DEKA and Johnson and Johnson's Independence Technology division has taken this matter seriously and built iBOT to overcome this problem. iBOT has two sets of wheel so that it can climb and go down stairs without any problem. It equipped with gyroscopes so that it can stand on 2 wheels to reach something higher.

These gyroscopes features used in Solax Via to stand on two wheels and can be controlled by using user body. Solax Via will move forward, backwards, turn and remain stationary when user shift their body's center of gravity. Hand controls in the tiller will control to turn left or right. Via is built for user who like to play sport such as basketball that needs fast reaction to move and need both hand to play. So Solax provide a wheelchair that can move without joystick

Pride Quantum 6000 Rehab Power Wheelchair developed by Quantum Rehab ${ }^{\circledR}$ to provide almost the same features as iBOT. But quantum 6000 can't raise its seat level to reach something higher. Even though it's called rehab wheelchair, it not providing rehab exercise for the patient. Quantum 6000 has extra capability by reclining $85^{\circ}-175^{\circ}$ for the user to lay on their wheelchair. So the patient can do rehab while laying on it.

\section{ELECTRIC WHEELCHAIR FOR REHABILITATION}

Rehabilitation is an important process for the patient to recover after suffered a stroke. The effect is they have hard time to move their body parts based on what they desire. So they need to relearn to improve their movement to ease daily life and get back to work as soon as possible[65]. In rehabilitation process, there are physiotherapy treatments to do physical work such as to move their body part. In this treatment, patients taught by physiotherapist on how to move in a correct way, monitor to see any improvement and design type of rehabilitation exercise that suitable according to patient's condition. Full attention are needed to make sure speedy recovery progress. However, numbers of physiotherapist is a main constraint on giving full attention on each patients[66]. Rehabilitation tools are needed to replace them.

Shuang Chen, Fang-fa Fu and their team members comes out with an idea to build intelligent rehabilitation training tool which has tele-doctor-patient interaction system[47]. They installed 4 linear motors on electric wheelchair to provide lower limb training function and Bluetooth communication system to send information to the doctor or physiotherapist for monitoring patient's recovery process. Pressure sensor located at the foot rest and user needs to move their center of gravity to give different amount of pressure onto it. Different pressure will decide the movement of airplane to reach bombs and diamonds in a video game as in Figure 5. Patients will play and at the same time it becomes rehabilitation exercise for them.

For pediatrics, Laura Marchal-Crespo, Jan Furumasu and David J Reinkensmeyer developed a robotic wheelchair trainer to reduce time for hand-over-hand assistance from a skilled therapist called ROLY (Robot assisted Learning for Young drivers) as Figure 56 . Their robotic wheelchair trainer will move itself follow along a line on the floor using computer vision to show the correct joystick control technique. A mobile robot equipped with line following system placed at the front of the wheelchair to attract user's attention to catch it as motivation for them to do the training. Tested on two groups of children, one is a normal children and children with a severe motor impairment due to cerebral palsy. Normal children drive the ROLY without guidance by joystick in front of them but for cerebral palsy impairment children guidance is provided. After the training session, cerebral palsy impairment children improved steering ability better than normal children.

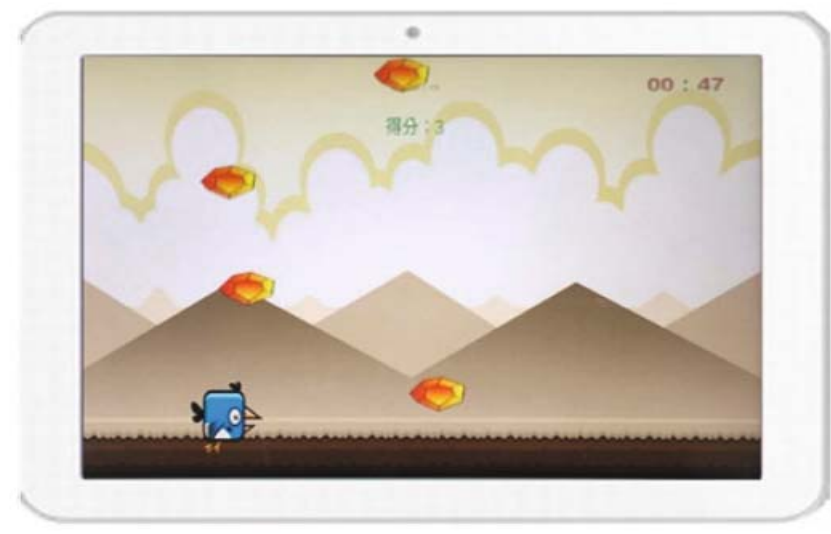

Fig. 5. Interface of Rehabilitation Game 
Table 6. Rehabilitation Wheelchair

\begin{tabular}{|l|l|c|l|l|l|c|}
\hline No & References & $\begin{array}{l}\text { Degree of } \\
\text { freedom }\end{array}$ & $\begin{array}{l}\text { Target } \\
\text { group }\end{array}$ & Function & Modifications & $\begin{array}{l}\text { Year } \\
\text { Published }\end{array}$ \\
\hline 1 & {$[67]$} & 2 & paeds & Rehab & $\begin{array}{l}\text { Line follower, } \\
\text { robot }\end{array}$ & 2010 \\
\hline 2 & {$[47]$} & 2 & adult & $\begin{array}{l}\text { Rehab and } \\
\text { mobility }\end{array}$ & $\begin{array}{l}\text { Tele-conference, } \\
\text { pressure sensor }\end{array}$ & 2017 \\
\hline
\end{tabular}

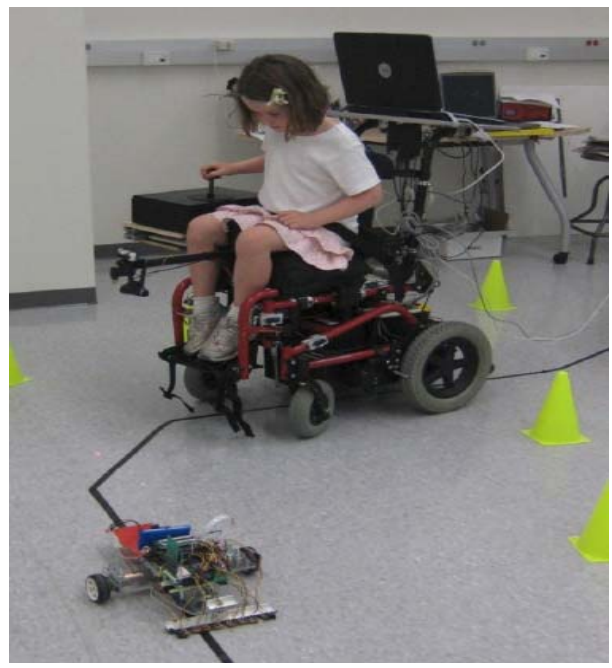

Figure 6. Roly

\section{CHALLENGE IN DEVELOPING WHEELCHAIR}

On January 12, 2010, an earthquake struck Haiti and lots of people died and injured. Some of them paralyzed and they need wheelchair to continue live their life. Due to cost, some of facilities neglected patients who need rehabilitation and refuse to treat them[68]. Cost is very important aspect researchers need to look into because not all patients has capacity to buy expensive rehabilitation tools [69-71].

Easy for maintenance and parts are available anywhere is one of the challenge in developing a wheelchair for spinal cord injury patients[72]. In a poor country, a wheelchair will be used in anywhere even it's not built for that kind of environment because of lack of equipment available on market[73]. Too high level of technology installed will make the wheelchair prone to damage and make it more difficult to maintain or repair. That's why the mechanism should be as simple as possible and spare part is available anywhere.

Keep patient motivated to continue the rehabilitation exercise must be considered by motion-based game interaction wheelchair. Different ages of user need different type of games[74]. As age increased, patient's ability will decrease due to reduction of muscle mass, stamina and strength[75]. Same things will happen to their hearing, vision and reaction will decrease from time to time [76]. Researcher should provide few type of games that can be selected based on user's age, abilities or the one that they are interested.

Each of wheelchair available on market must meet requirement from American National Standards Institute (ANSI) or Rehabilitation Engineering and Assistive Technology Society of North America (RESNA) standards to make sure all user are safe during operating the equipment. Any innovation done on electric wheelchair must be follow these requirement before tested on user in order to prevent bad things from happen.

\section{CONCLUSION}

Numbers of research on improving quality of life for spinal cord impairment patient shows humanity in our society still exist. Everybody can contribute to others in different ways to make sure these unlucky people are not left behind in every aspect. Advancement in technology contributing in building a better wheelchair for disabilities. As we can see, after technology for muscle contraction detector is available, the numbers of sensors installed in an electric wheelchair is reduced to only one. Better algorithm developed to reduced accident happens due to misread of signal by the sensors. And different approach used to increase motivation and recovery process for the patient to regain their ability back to return to work.

Manufacturers should be do collaboration with the researchers to market the innovated wheelchair to reach more people who are suffering same disability. They may manufacture the same innovated wheelchair for commercialization or gather all the information and result done by researchers to produce a better wheelchair that can fulfil the need from different group of disabilities. Combinations from different sensors needs different hardware to make it a system but all of them produce same result in navigating the wheelchair. Almost all produce a good result and just a few need small improvements to make it perfect. 
Adding rehabilitation features into a wheelchair is a good innovation to reduce the cost, space and time for patients to speed up their recovery process. Cost for them to go to rehabilitation can be reduced if they are able to do the exercise at home and eliminate space to place rehabilitation tools. And most important thing is save time. They can do rehabilitation exercise during living their daily life by riding the wheelchair.

\section{REFERENCES}

[1] Jones, M.L. and J.A. Sanford, People with mobility impairments in the United States today and in 2010. Assistive Technology, 1996. 8(1): p. 43-53.

[2] Ding, D. and R.A. Cooper, Electric powered wheelchairs. IEEE Control Systems, 2005. 25(2): p. 22-34.

[3] Cooper, R.A., Wheelchair selection and configuration. 1998: Demos Medical Publishing.

[4] Simpson, R., et al., The smart wheelchair component system. Journal of Rehabilitation Research and Development, 2004. 41(3B): p. 429.

[5] Ashok, S., High-level hands-free control of wheelchair-a review. Journal of Medical Engineering \& Technology, 2017. 41(1): p. $46-64$.

[6] Levine, S.P., et al., The NavChair assistive wheelchair navigation system. IEEE transactions on rehabilitation engineering, 1999. 7(4): p. $443-451$.

[7] Simpson, R.C. and S.P. Levine, Voice control of a powered wheelchair. IEEE Transactions on Neural Systems and Rehabilitation Engineering, 2002. 10(2): p. 122-125.

[8] Sarabia, M. and Y. Demiris. A humanoid robot companion for wheelchair users. in International Conference on Social Robotics. 2013. Springer.

[9] Butler, C., G.A. Okamoto, and T.M. McKay, POWERED MOBILITY FOR VERY YOUNG DISABLED CHILDREN. Developmental Medicine \& Child Neurology, 1983. 25(4): p. 472-474

[10] Connell, J. and P. Viola. Cooperative control of a semi-autonomous mobile robot. in Proc. IEEE Int'l Conf. on Robotics and Automation. 1990.

[11] Bourhis, G., et al. Assisted navigation for a powered wheelchair. in Systems, Man and Cybernetics, 1993.'Systems Engineering in the Service of Humans', Conference Proceedings., International Conference on. 1993. IEEE.

[12] Miller, D.P. and M.G. Slack, Design and testing of a low-cost robotic wheelchair prototype. Autonomous robots, 1995. 2(1): p. 77-88.

[13] Yoder, J.-D., E.T. Baumgartner, and S.B. Skaar, Initial results in the development of a guidance system for a powered wheelchair. IEEE Transactions on Rehabilitation Engineering, 1996. 4(3): p. 143-151.

[14] Kollmann, J., et al. Navigation of a kinematically restricted wheelchair by the parti-game algorithm. in Manchester University. 1997. Citeseer.

[15] Katevas, N.I., et al., The autonomous mobile robot SENARIO: a sensor aided intelligent navigation system for powered wheelchairs. IEEE Robotics \& Automation Magazine, 1997. 4(4): p. 60-70.

[16] Bühlmeier, A., et al. Application of a local learning rule in a wheelchair robot. in Third International Conference on Neural Networks and their Applications (Neurap97). 1997. Citeseer.

[17] Yanco, H.A., Wheelesley: A robotic wheelchair system: Indoor navigation and user interface, in Assistive technology and artificial intelligence. 1998, Springer. p. 256-268.

[18] Seki, H., et al. Autonomous/semi-autonomous navigation system of a wheelchair by active ultrasonic beacons. in Robotics and Automation, 2000. Proceedings. ICRA'00. IEEE International Conference on. 2000. IEEE.

[19] Prassler, E., J. Scholz, and P. Fiorini, A robotics wheelchair for crowded public environment. IEEE Robotics \& Automation Magazine, 2001. 8(1): p. 38-45.

[20] Mazo, M., An integral system for assisted mobility. IEEE Robotics and Automation Magazine, 2001. 8(1): p. 46-56.

[21] Matsumotot, Y., T. Ino, and T. Ogsawara. Development of intelligent wheelchair system with face and gaze based interface. in Robot and Human Interactive Communication, 2001. Proceedings. 10th IEEE International Workshop on. 2001. IEEE.

[22] Boy, E.S., C.L. Teo, and E. Burdet. Collaborative wheelchair assistant. in Intelligent Robots and Systems, 2002. IEEE/RSJ International Conference on. 2002. IEEE.

[23] Kuno, Y., N. Shimada, and Y. Shirai, Look where you're going [robotic wheelchair]. IEEE Robotics \& Automation Magazine, 2003. 10(1): p. 26-34.

[24] Moon, I., et al. Intelligent robotic wheelchair with EMG-, gesture-, and voice-based interfaces. in Intelligent Robots and Systems, 2003.(IROS 2003). Proceedings. 2003 IEEE/RSJ International Conference on. 2003. IEEE.

[25] Parikh, S.P., et al. Human robot interaction and usability studies for a smart wheelchair. in Intelligent Robots and Systems, 2003.(IROS 2003). Proceedings. 2003 IEEE/RSJ International Conference on. 2003. IEEE.

[26] Zeng, Q., et al., A collaborative wheelchair system. IEEE Transactions on Neural Systems and Rehabilitation Engineering, 2008. 16(2): p. 161-170.

[27] Zeng, Q., et al. Design of a collaborative wheelchair with path guidance assistance. in Proceedings 2006 IEEE International Conference on Robotics and Automation, 2006. ICRA 2006. 2006. IEEE.

[28] Zeng, Q., et al. Evaluation of the collaborative wheelchair assistant system. in 2007 IEEE 10th International Conference on Rehabilitation Robotics. 2007. IEEE.

[29] Montesano, L., et al., Towards an intelligent wheelchair system for users with cerebral palsy. IEEE Transactions on Neural Systems and Rehabilitation Engineering, 2010. 18(2): p. 193-202.

[30] Soh, H. and Y. Demiris. Involving young children in the development of a safe, smart paediatric wheelchair. in ACM/IEEE HRI-2011 Pioneers Workshop, Lausanne, Switzerland. 2011. Citeseer.

[31] Sasou, A. Powered Wheelchair Control Using Acoustic-Based Recognition of Head Gesture Accompanying Speech. in INTERSPEECH. 2011.

[32] Tomari, M.R.M., Y. Kobayashi, and Y. Kuno, Development of smart wheelchair system for a user with severe motor impairment. Procedia Engineering, 2012. 41: p. 538-546.

[33] Suryawanshi, S., J. Chitode, and S. Pethakar, Voice Operated Intelligent Wheelchair. International Journal of Advanced Research in Computer science and software engineering, 2013.3(5): p. 1.

[34] Bourbakis, N., et al. An autonomous intelligent wheelchair for assisting people at need in smart homes: A case study. in Information, Intelligence, Systems and Applications (IISA), 2015 6th International Conference on. 2015. IEEE.

[35] Champaty, B., et al. Development of EOG based human machine interface control system for motorized wheelchair. in Emerging Research Areas: Magnetics, Machines and Drives (AICERA/iCMMD), 2014 Annual International Conference on. 2014. IEEE.

[36] Lee, K.-m., et al., Power-Assisted Wheelchair With Gravity and Friction Compensation. IEEE Transactions on Industrial Electronics, 2016. 63(4): p. 2203-2211.

[37] Veerubhotla, A., et al., Mobility assistance for patients with Quadriplegia. Journal of Scientific \& Industrial Research, 2015. 74: p. $102-$ 104. 
[38] Yi, Z., F. Xiaolin, and L. Yuan, Intelligent wheelchair system based on sEMG and head gesture. The Journal of China Universities of Posts and Telecommunications, 2015. 22(2): p. 74-95.

[39] Shen, J., et al. A low-cost tele-presence wheelchair system. in Intelligent Robots and Systems (IROS), 2016 IEEE/RSJ International Conference on. 2016. IEEE.

[40] Yanmin, L., et al. Research on automatic tracking caregivers of intelligent wheelchair. in Control and Decision Conference (CCDC), 2016 Chinese. 2016. IEEE.

[41] Njah, M. and M. Jallouli, Fuzzy-EKF Controller for Intelligent Wheelchair Navigation. Journal of Intelligent Systems, 2016. 25(2): p. $107-121$.

[42] Gupta, P., et al., Accelerometer Based Hand Gesture Controlled Wheelchair. Imperial Journal of Interdisciplinary Research, 2016. 2(11).

[43] Amor, N.B., F.B. Taher, and M. Jallouli, A Novel and Robust Wheelchair Navigation System. International Journal of Computer Science and Information Security, 2016. 14(5): p. 273.

[44] Soni, G.K., et al., Hand Gesture Recognition Based Wheel Chair Direction Control Using AVR Microcontroller. Hand, 2016. 5(3).

[45] Devigne, L., et al. Low complex sensor-based shared control for power wheelchair navigation. in Intelligent Robots and Systems (IROS), 2016 IEEE/RSJ International Conference on. 2016. IEEE.

[46] Gillham, M., et al., Developing Effective Intelligent Assistance for the Powered Wheelchair User. 2016.

[47] Chen, S., et al., Development of a Lower Limb Rehabilitation Wheelchair System Based on Tele-Doctor-Patient Interaction, in Wearable Sensors and Robots. 2017, Springer. p. 211-223.

[48] Chauhan, R., et al. Study of implementation of Voice Controlled Wheelchair. in Advanced Computing and Communication Systems (ICACCS), 2016 3rd International Conference on. 2016. IEEE.

[49] Malik, N.K. and V. Singh, A human inspired cognitive wheelchair navigation system. International Journal of Human Factors Modelling and Simulation, 2016. 5(3): p. 263-284.

[50] Dalsaniya, A.K. and D.H. Gawali. Smart phone based wheelchair navigation and home automation for disabled. in Intelligent Systems and Control (ISCO), 2016 10th International Conference on. 2016. IEEE.

[51] Abiyev, R.H., et al., Brain-Computer Interface for Control of Wheelchair Using Fuzzy Neural Networks. BioMed Research International, 2016. 2016.

[52] Al Mamun, S., et al. Terrain Recognition for Smart Wheelchair. in International Conference on Intelligent Computing. 2016. Springer.

[53] Kaiser, M.S., et al., A Neuro-Fuzzy Control System Based on Feature Extraction of Surface Electromyogram Signal for Solar-Powered Wheelchair. Cognitive Computation, 2016: p. 1-9.

[54] Omrane, H., M.S. Masmoudi, and M. Masmoudi, Fuzzy Logic Based Control for Autonomous Mobile Robot Navigation. Computational Intelligence and Neuroscience, 2016. 2016.

[55] Sathish, S., et al., Control of Robotic Wheel Chair using EMG Signals for Paralysed Persons. Indian Journal of Science and Technology, 2016. 9(1).

[56] Shah, K., V. Shah, and C. Shah, Head Movement Based Wheelchair. Imperial Journal of Interdisciplinary Research, 2016. 2(5).

[57] Jang, G., et al., EMG-Based Continuous Control Scheme With Simple Classifier for Electric-Powered Wheelchair. IEEE Transactions on Industrial Electronics, 2016. 63(6): p. 3695-3705.

[58] Lee, G., K. Kim, and J. Kim, Development of hands-free wheelchair device based on head movement and bio-signal for quadriplegic patients. International Journal of Precision Engineering and Manufacturing, 2016. 17(3): p. 363-369.

[59] Ishii, C. and R. Konishi. A Control of Electric Wheelchair Using an EMG Based on Degree of Muscular Activity. in Digital System Design (DSD), 2016 Euromicro Conference on. 2016. IEEE.

[60] Argall, B.D. Modular and adaptive wheelchair automation. in Experimental Robotics. 2016. Springer.

[61] Megalingam, R.K., et al., IR Sensor-Based Gesture Control Wheelchair for Stroke and SCI Patients. IEEE Sensors Journal, 2016. 16(17): p. 6755-6765.

[62] Lin, Y.-T. and C.-H. Kuo. Development of SSVEP-based intelligent wheelchair brain computer interface assisted by reactive obstacle avoidance. in 2016 IEEE International Conference on Industrial Technology (ICIT). 2016. IEEE.

[63] Lopes, A., et al., A New Hybrid Motion Planner: Applied in a Brain-Actuated Robotic Wheelchair. IEEE Robotics \& Automation Magazine, 2016. 23(4): p. 82-93.

[64] Malik, A.Q. and J. Ahmad, Retina based mouse control (RBMC). World Academy of Science, Engineering and Technology, 2007. 31: p. 318-322.

[65] Ismail, R.B., S.B.S. Salehudin, and S.N.B. Deraman. Design of Wheelchair Physiotherapy Rehabilitation Treatment. in 2015 Innovation \& Commercialization of Medical Electronic Technology Conference (ICMET). 2015. IEEE.

[66] Aiken, A.B., et al., Easing the burden for joint replacement wait times: the role of the expanded practice physiotherapist. Healthc Q, 2008. 11(2): p. 62-66.

[67] Marchal-Crespo, L., J. Furumasu, and D.J. Reinkensmeyer, A robotic wheelchair trainer: design overview and a feasibility study. Journal of neuroengineering and rehabilitation, 2010.7(1): p. 1 .

[68] Merin, O., et al., The Israeli field hospital in Haiti- ethical dilemmas in early disaster response. New England Journal of Medicine, 2010. 362(11): p. e38.

[69] Guimaraes, E. and W.C. Mann, Evaluation of pressure and durability of a low-cost wheelchair cushion designed for developing countries. International Journal of Rehabilitation Research, 2003. 26(2): p. 141-143.

[70] Ooi, A. and P. Julia, The use of unconventional pressure redistributing cushion in spinal cord injured individuals. Spinal cord, 2011. 49(12): p. 1203-1205.

[71] Díaz, I., J.J. Gil, and E. Sánchez, Lower-limb robotic rehabilitation: literature review and challenges. Journal of Robotics, 2011. 2011.

[72] Burns, A.S. and C. O'Connell, The challenge of spinal cord injury care in the developing world. The journal of spinal cord medicine, 2012. 35(1): p. 3-8.

[73] Levy, L., et al., Problems, struggles and some success with spinal cord injury in Zimbabwe. Spinal Cord, 1998. 36(3).

[74] Gerling, K.M., R.L. Mandryk, and M.R. Kalyn. Wheelchair-based game design for older adults. in Proceedings of the 15th International ACM SIGACCESS Conference on Computers and Accessibility. 2013. ACM.

[75] Ketcham, C.J., et al., Age-related declines in motor control. Handbook of the psychology of aging, 2001. 5: p. 313-348.

[76] Czaja, S.J. and C.C. Lee, Information technology and older adults. 2009: CRC Press. 